\title{
Fine Thermotactic Discrimination between the Optimal and Slightly Cooler Temperatures via a TRPV Channel in Chordotonal Neurons
}

\author{
Young Kwon, ${ }^{\star}$ Wei L. Shen, ${ }^{\star}$ Hye-Seok Shim, and Craig Montell \\ Departments of Biological Chemistry and Neuroscience, Center for Sensory Biology, The Johns Hopkins University School of Medicine, Baltimore, \\ Maryland, 21205
}

\begin{abstract}
Animals select their optimal environmental temperature, even when faced with alternatives that differ only slightly. This behavior is critical as small differences in temperature of only several degrees can have a profound effect on the survival and rate of development of poikilothermic animals, such as the fruit fly. Here, we demonstrate that Drosophila larvae choose their preferred temperature of $17.5^{\circ} \mathrm{C}$ over slightly cooler temperatures $\left(14-16^{\circ} \mathrm{C}\right)$ through activation of chordotonal neurons. Mutations affecting a transient receptor potential (TRP) vanilloid channel, Inactive (Iav), which is expressed specifically in chordotonal neurons, eliminated the ability to choose $17.5^{\circ} \mathrm{C}$ over $14-16^{\circ} \mathrm{C}$. The impairment in selecting $17.5^{\circ} \mathrm{C}$ resulted from absence of an avoidance response, which is normally mediated by an increase in turns at the lower temperatures. We conclude that the decision to select the preferred over slightly cooler temperatures requires iav and is achieved by activating chordotonal neurons, which in turn induces repulsive behaviors, due to an increase in high angle turns.
\end{abstract}

\section{Introduction}

Animals are capable of discerning small differences above and below their preferred ambient temperature, and this ability is especially important for organisms, such as insects, whose internal body temperature rapidly equilibrates with the environmental temperature. However, the molecular and cellular bases by which animals survey their thermal landscapes and decide on how to respond behaviorally to different temperature alternatives are incompletely understood.

A key class of temperature sensors is an evolutionarily conserved set of cation channels, referred to as transient receptor potential (TRP) channels (Venkatachalam and Montell, 2007). These proteins are global mediators of sensory input and thereby control a variety of animal behaviors. In Drosophila three TRP channels participate in the responses to warm or hot temperatures in the noxious range (Tracey et al., 2003; Lee et al., 2005; Rosenzweig et al., 2005; Hamada et al., 2008). We have shown recently that Drosophila larvae are sensitive to small deviations from their preferred temperature of $\sim 17.5-18^{\circ} \mathrm{C}$, and TRPA 1 is critical for enabling larvae to select these optimal temperatures over slightly warmer temperatures $\left(\leq 24^{\circ} \mathrm{C}\right)$ (Kwon et al., 2008). In addition, two TRPC channels, TRP and TRPL have been reported to be involved in choosing the preferred temperature over slightly cooler temperatures (Rosenzweig et al., 2008).

\footnotetext{
Received March 30, 2010; revised June 9, 2010; accepted June 18, 2010.

This work was supported by grants from the National Eye Institute (EY010852) and the National Institute of General Medical Sciences (GM085335).

*Y.K. and W.L.S. contributed equally to this work.

Correspondence should be addressed to Craig Montell at the above address. E-mail: cmontell@jhmi.edu.

DOI:10.1523/JNEUROSCI.1631-10.2010

Copyright $\odot 2010$ the authors $\quad 0270-6474 / 10 / 3010465-07 \$ 15.00 / 0$
}

Here, we conducted a comprehensive screen for Drosophila TRP channels that enable larvae to choose their optimal temperature of $17.5^{\circ} \mathrm{C}$ over mildly cooler temperatures $\left(14-16^{\circ} \mathrm{C}\right)$. We found that a TRP vanilloid channel, Iav, was required in chordotonal neurons for selecting 17.5 over $14-16^{\circ} \mathrm{C}$. Moreover, both Iav and the chordotonal neurons were required for selecting the optimal temperatures by inducing the larvae to increase turning angles, thereby avoiding the cooler temperatures.

\section{Materials and Methods}

Preparing third instar larvae for thermotaxis assay. We prepared larvae for the thermotaxis assay as described previously (Kwon et al., 2008): http:// www.natureprotocols.com/2008/07/28/assaying_thermotaxis_behavior. php. Briefly, the flies and larvae were reared at $25^{\circ} \mathrm{C}$ and were not exposed to $\mathrm{CO}_{2}$ at any time. We removed the third instar larvae from the food and washed them with $15 \%$ sucrose to remove remaining food, and then with $\mathrm{H}_{2} \mathrm{O}$ to remove the sucrose. We allowed the larvae to recover for $30 \mathrm{~min}$ at room temperature $\left(\sim 22^{\circ} \mathrm{C}\right)$ before assaying thermotactic behavior. We applied moisture to avoid desiccation.

Thermotactic behavioral assay. We analyzed thermotactic behavior as described previously (Kwon et al., 2008): http://www.natureprotocols. com/2008/07/28/assaying_thermotaxis_behavior.php. Briefly, we added $40-100$ larvae ( $\sim 95 \%$ third instar) to the test plates. Unless specified otherwise, we placed the larvae along the middle of the plates containing $2 \%$ agarose. The experiments were conducted under ambient light. After 15 min, we photographed the plates and calculated the preference index (P.I.): P.I. $=\left\{\right.$ (number of larvae on $17.5^{\circ} \mathrm{C}$ side $)-($ number of larvae on the other side with the variable temperature) $\} \div$ (total number of larvae on each side of the test plate).

Light-dark choice assays using animals expressing channelrhodopsin 2. We reared the larvae on standard food at $25^{\circ} \mathrm{C}$ with or without $50 \mu \mathrm{M}$ all-trans-retinal (Sigma, R2500). We avoided exposing the larvae to light by wrapping vials with foil. To conduct the light-dark choice assays, we 
prepared the third instar larvae as described above and as detailed previously (Kwon et al., 2008): http://www.natureprotocols.com/2008/07/28/ assaying_thermotaxis_behavior.php, except that we collected and washed the larvae under dim light to minimize light exposure. Ten to 15 larvae were placed in the middle of a $3.5 \mathrm{~cm}$ cell culture dish covered with $2 \mathrm{ml}$ of $2 \%$ agarose (see Fig. $4 A, B$ ). To avoid excessive heat, we illuminated half the dish with 20 pulses of light $\left(5 \mathrm{~s}\right.$ each; $0.03 \mathrm{~mW} / \mathrm{mm}^{2}$ ), interspersed by $2.5 \mathrm{~s}$ dark intervals. The light was a $100 \mathrm{~W}$ quartz tungsten halogen bulb housed in an Oriel Apex QTH projector (Newport). The programming was performed using LabChart software in conjunction with PowerLab 4/30 (ADInstruments). The larvae on the light and dark sides were counted and the P.I. values calculated: $\{$ (number of larvae on dark side) - (number of larvae on light side) $\} \div$ (total number of larvae on each side of the test plate). The larvae were prepared and the assays were performed at room temperature $\left(\sim 22^{\circ} \mathrm{C}\right)$.

Constructs for generating transgenic flies. To generate UAS-iav flies, we amplified the coding region of iav by RT-PCR and subcloned the CDNA between the NotI and XbaI sites of pUAST. To generate the iav-GAL4 transgenic line, we excised the GAL4 sequence and the $h s p 703^{\prime}$ UTR from pGATB (Brand and Perrimon, 1993) using BamHI and SpeI and subcloned the DNA between the BamHI and XbaI sites of pCasper4GAL4. We amplified $\sim 3 \mathrm{~kb}$ flanking the $5^{\prime}$ end of $i a v$, which we subcloned between the NotI and BamHI sites of pCasper4-GAL4.

Movement trace analysis. To determine the turning angles $(\theta)$ and the total vectoral movement, we tracked movement on temperature preference test plates using a digital camera. We processed the movies using QuickTime Pro 7. The intervals between consecutive frames were $5.1 \mathrm{~s}$. We manually tracked the position of the individual larval head region between the end of the first and tenth frames (45.9 s) using NIH ImageJ software and MTrackJ plugin (Rasband WS, ImageJ, U.S. National Institutes of Health, Bethesda, MD, http://rsb.info.nih.gov/ij/, 1997-2009). The larvae remained on the test plates 3 min before initiating tracking. We discarded the trace if movement was disturbed by the test plate border or by interactions with other larvae. We calculated each $\theta$ by establishing the vectoral direction (by comparing larval head positions) between the beginning of two consecutive frames $\left[P_{(\mathrm{N}-1)}\right.$ and $P_{(\mathrm{N})}$ and $\left.P_{(\mathrm{N}+1)}\right]$ (see Fig. $4 F$ ) and the beginning of the $P_{(\mathrm{N})}$ and $P_{(\mathrm{N}+1)}$ frames. We analyzed 88 individual directional deviations each.

To determine the movement speed $(\mathrm{mm} / \mathrm{s})$, we used 11 traces. We first determined the total distance traveled $(\mathrm{mm})$ by adding together the individual connections between 10 consecutive frames. We divided the total distance traveled by the seconds (45.9) between the end of the first and 10th frames. The vectoral travel distance was established by connecting the positions at the end of the first and 10th frames in a trace with a single line.

Fly stocks. The wild-type strain was Canton S. We obtained the following flies from the Bloomington Stock Center (stock numbers): $i a v^{1}$ (6029), $\operatorname{trpl}^{\text {MB03075 }}$ (23512) UAS-ChR2 (9681) (Schroll et al., 2006) $b t v^{B G 01771}(12589)$ and Df(1)pod1 ${ }^{\Delta 17}(8749)$. We obtained $n a n^{36 a}$ from C. Kim, Chonnam National University, Gwangju, Korea, $p y x^{3}$ from J. Kim, Korea Advanced Institute of Science and Technology, Daejeon, Korea (Lee et al., 2005), pain $^{2}$ from W. D. Tracey, Duke University Medical Center, Durham, NC (Tracey et al., 2003), the trpA1-GAL4 line from P. A. Garrity, Brandeis University, Waltham, MA (Rosenzweig et al., 2005), $i a v^{l} ; \mathrm{P}\left[\mathrm{iav}^{+}\right]$from J. Hirsh, University of Virginia, Charlottesville, VA, and $a t{ }^{W}$ from B. A. Hassan, VIB, Katholieke Universiteit, Leuven, Belgium (Choi et al., 2009). The following trp stocks were described previously: $\operatorname{trp}^{P 343}$ (Wang et al., 2005), $\operatorname{tr} p^{47}$ (Wang et al., 2005) $\operatorname{tr} p^{302}$ (Niemeyer et al., 1996), $\operatorname{trpA1}^{1}$ (Kwon et al., 2008), pyx ${ }^{3}$ (Lee et al., 2005), pain $^{2}$ (Tracey et al., 2003), iav ${ }^{1}$ (Gong et al., 2004), iav ${ }^{3621}$ (Gong et al., 2004), nan ${ }^{36 a}$ (Kim et al., 2003), trpml $^{1}$ (Venkatachalam et al., 2008), $a m o^{1}$ (Watnick et al., 2003), nomp $C^{2}$, nomp $C^{3}$ (Walker et al., 2000) and $\operatorname{trpm}^{1}$ (Hofmann et al., 2010). The unpublished trp $\gamma^{1}$ and $w t r w^{e x}$ mutants were provided by Q. Ren and X. Wang, respectively, Johns Hopkins University School of Medicine, Baltimore, MD.

Statistics. For single pair comparisons, we used the unpaired Student's $t$ test in Excel 2007 (Microsoft). For multiple comparisons between wildtype and test groups, we used one-way ANOVA with the Dunnett's method using the Minitab 15 (Microsoft) default parameters (one-way ANOVA unstacked, family error rate: 5). For other multiple compari- sons, we used one-way ANOVA with the Tukey or Tukey-Kramer test (with unequal sample numbers) in Origin 7.0 (OriginLab).

\section{Results}

\section{Requirement for a TRPV channel, IAV, for selecting the optimal temperature over slightly cool but not cold temperatures}

To systematically address the requirements for TRP channels for selecting $17.5^{\circ} \mathrm{C}$ over mildly cooler temperatures, we examined mutations affecting each of the 13 Drosophila TRP channels by performing two-way choice tests. We released larvae at the center of plates between $14^{\circ}$ and $17.5^{\circ} \mathrm{C}$ zones and allowed them to choose between the two temperatures for $15 \mathrm{~min}$ (Fig. $1 \mathrm{~A}$ ). If all larvae migrated to the $17.5^{\circ} \mathrm{C}$ side, the P.I. would be 1.0 , while a complete preference for $14^{\circ} \mathrm{C}$ would result in a P.I. of -1.0 . The P.I. would be 0 if there were an equal number of larvae on both sides of the test plate.

Elimination of any of the four TRPA channels, TRPM, TRPP (AMO), TRPN (NOMPC) or TRPML did not reduce the preference for $17.5^{\circ} \mathrm{C}$ (Fig. $1 \mathrm{~B}$ ). Mutation of the gene encoding the third TRPC channel, TRP $\gamma$, caused a slight, but statistically insignificant decrease in the P.I. (Fig. $1 B$ ). As reported previously, disruption of trpl abolished the preference for $17.5^{\circ} \mathrm{C}$ (Rosenzweig et al., 2008) (Fig. $1 B, C$ ). However, the temperature preferences of two strong trp alleles, $\operatorname{tr} p^{P 343}$ and $\operatorname{tr} p^{47}$, were indistinguishable from wildtype larvae (Fig. $1 B, D$ ). Nevertheless, the previous finding that trp contributed to cool sensation was not definitive since thermotaxis was normal in larvae harboring the trp mutation in trans with a deficiency that removed the trp locus (Rosenzweig et al., 2008).

We found that mutations that disrupted either of the TRPV genes, $i a v^{1}$ or $n a n^{36 a}$, eliminated the ability of the larvae to discriminate between $14^{\circ}$ and $17.5^{\circ} \mathrm{C}$ (Fig. $1 \mathrm{~B}$ ). These results were surprising since mammalian TRPM and TRPA channels are known or implicated to function in the sensation of low temperatures, while TRPV channels participate in the responses to modestly warm temperatures, or to noxious heat (Venkatachalam and Montell, 2007).

Since iav and nan mutants are sedentary, the impairments in thermotaxis could be due to the reduced movements rather than to defects in temperature sensation. Indeed, both $i a v^{1}$ and $n a n^{36 a}$ moved more slowly than wild-type larvae at either $14^{\circ}$ or $17.5^{\circ} \mathrm{C}$ (Fig. $1 E$ ). Therefore, we tested the effects on the P.I. after changing the release zone on the temperature selection test plate. Instead of placing the larvae in the middle of the test plate, we introduced the larvae at the extreme ends of the $14^{\circ} \mathrm{C}$ or the $17.5^{\circ} \mathrm{C}$ sides ( $\mathrm{B}$ and $\mathrm{C}$ sites, Fig. $1 \mathrm{~A}$ ). Wild-type larvae showed a preference for $17.5^{\circ} \mathrm{C}$, regardless of the release site, although the P.I. was reduced slightly if they were placed at the end of the $14^{\circ} \mathrm{C}$ side, presumably due to slower migration at this temperature (Fig. $1 A, F)$. However, the P.I. of nan ${ }^{36 a}$ larvae was strongly dependent on their initial placement site on the test plate. When we introduced $n a n^{36 a}$ larvae at the end of the $14^{\circ}$ or $17.5^{\circ} \mathrm{C}$ sides, most of larvae stayed in the $14^{\circ}$ or $17.5^{\circ} \mathrm{C}$ zones respectively (Fig. $1 \mathrm{~F})$. Consequently, we could not discern whether or not nan was impaired in the selection of $17.5^{\circ}$ over $14^{\circ} \mathrm{C}$. Contrary to these results, the $i a v^{l}$ larvae were randomly distributed on the test plates (P.I. values near 0$)$, regardless of where they were placed on the test plates (Fig. $1 A, F$ ). These findings indicate that iav larvae were impaired in the discrimination of the optimal temperature over $14^{\circ} \mathrm{C}$.

To provide further evidence that iav was required for choosing $17.5^{\circ}$ over $14^{\circ} \mathrm{C}$, we tested another iav allele $\left(\right.$ iav $\left.^{3621}\right)$. In addition, we analyzed both $i a v^{1}$ and $i a v^{3621}$ in trans with a deficiency (Df) that spanned the iav locus. We found that $i a v^{3621}, i a v^{1} / \mathrm{Df}$ and 
A

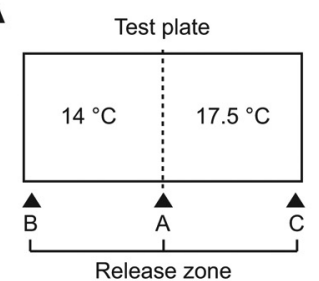

P.I. $=\frac{\left.\text { (no. at } 17.5^{\circ} \mathrm{C}\right)-\left(\text { no. at } 14^{\circ} \mathrm{C}\right)}{\left(\text { no. at } 17.5^{\circ} \mathrm{C}\right)+\left(\text { no. at } 14^{\circ} \mathrm{C}\right)}$

B
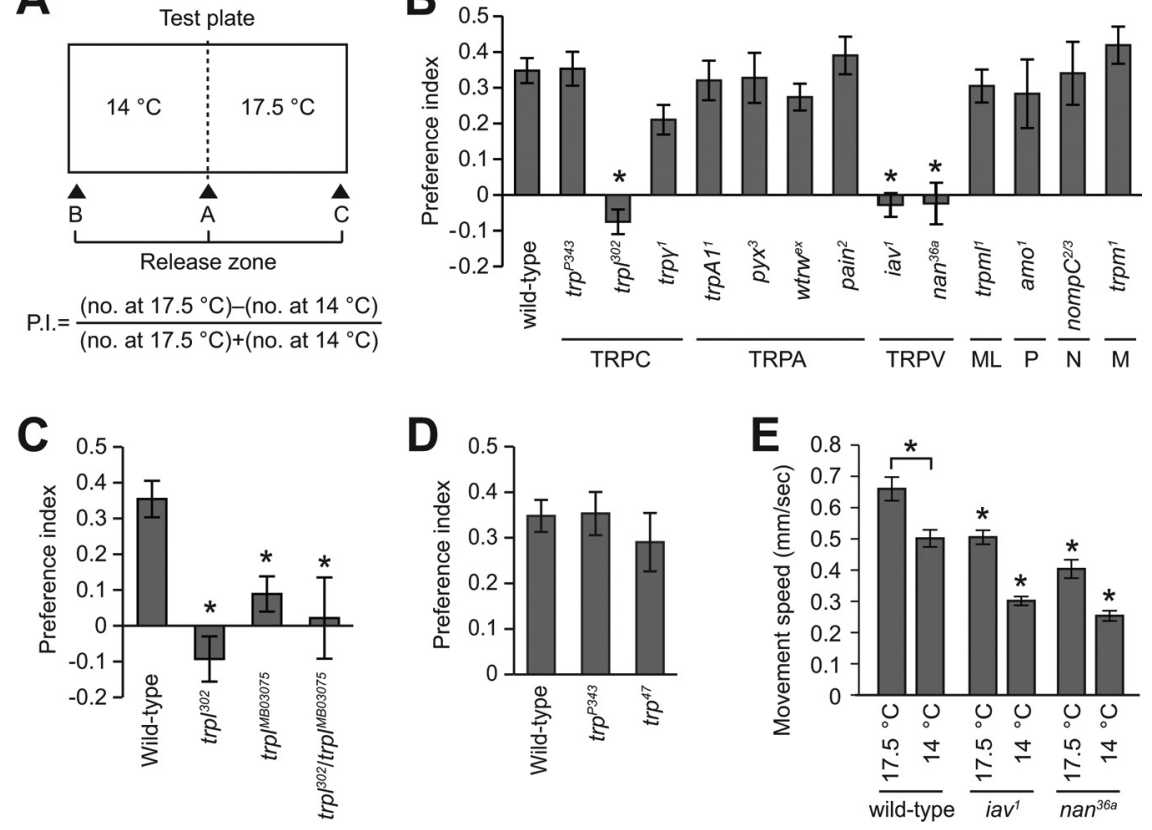

$\mathbf{F}$

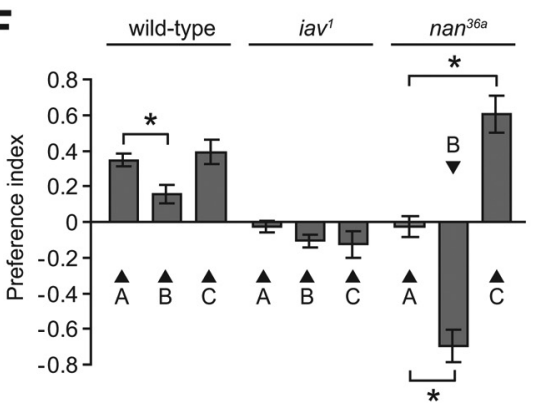

Figure 1. Requirement for iav for discriminating $17.5^{\circ} \mathrm{C}$ from modestly cooler temperatures. $A$, Schematic of the test plate. The formula for the P.I. is shown. B, Survey of TRPs functioning in the discrimination between $17.5^{\circ}$ and $14^{\circ} \mathrm{C}$. Preferences for $17.5^{\circ}$ and $14^{\circ} \mathrm{C}$ would result in positive and negative P.I. values, respectively. If there were no preference, the P.I. would be 0 . C, Selection of $17.5^{\circ} \mathrm{C}$ required trpl. D, Thermotaxis did not require trp. $\boldsymbol{E}$, Comparison of movement speeds. The movement speeds $(\mathrm{mm} / \mathrm{s})$ were calculated by dividing the total distance traveled $(\mathrm{mm})$ over 9 video frames $(45.9 \mathrm{~s})$. $\boldsymbol{F}$, The $17.5^{\circ}$ versus $14^{\circ} \mathrm{C}$ P.I. values after releasing the larvae in the indicated zones $(A, B$, or $C$; see $A) . G$, Characterization of $17.5^{\circ}$ versus $14^{\circ} \mathrm{C}$ preferences of iav alleles and iav $^{1}$ in trans with a deficiency (Df) chromosome (Bloomington stock 8749). P[iav $\left.{ }^{+}\right]$is the wild-type iav genomic rescue transgene. The asterisk indicates significant differences $(p<0.05)$ between the indicated pairs of data. If there are no brackets, the asterisk indicates significant differences with wild type.

$\mathrm{iav}^{3621} / \mathrm{Df}$ larvae all showed the same inability to select $17.5^{\circ}$ over $14^{\circ} \mathrm{C}$ (Fig. 1G). Furthermore, introduction of a wild-type genomic transgene $\left(\mathrm{P}\left[\mathrm{iav}^{+}\right]\right)$rescued the thermotaxis defect in the iav ${ }^{l}$ mutant (Fig. $1 G$ ). The combination of these data demonstrated that iav was required for thermotaxis in the cool range.

In addition to selecting $17.5^{\circ}$ over $14^{\circ} \mathrm{C}$, wild-type larvae chose $17.5^{\circ} \mathrm{C}$ over other cool temperatures, at least down to $12^{\circ} \mathrm{C}$ (Fig. $2 A, B)$. Discrimination of temperatures lower than $12^{\circ} \mathrm{C}$ was difficult to assess due to diminishing larval migration at lower temperatures (data not shown). Therefore, we tested whether iav was required for selecting $17.5^{\circ} \mathrm{C}$ over $12^{\circ}$ and $16^{\circ} \mathrm{C}$. We found that the ability of $i a v^{l}$ to choose $17.5^{\circ}$ over $16^{\circ} \mathrm{C}$ was also eliminated, as well as the discrimination between two cool temperatures $\left(14.5^{\circ}\right.$ vs $16^{\circ} \mathrm{C}$; Fig. $2 \mathrm{~A}$ ). However, the mutant animals exhibited a normal preference for $17.5^{\circ}$ over $12^{\circ} \mathrm{C}$ (Fig. $2 \mathrm{~B}$ ). As we have shown recently, $\mathrm{iav}^{1}$ larvae displayed normal selection of $17.5^{\circ} \mathrm{C}$ over comfortably warm temperatures, such as $22^{\circ}$ and $24^{\circ} \mathrm{C}$ (Fig. $2 \mathrm{C}$ ) (Kwon et al., 2008). These latter results were not surprising given the requirement for $\operatorname{trp} A 1$ for thermotactic behavior in this tem- perature range (Fig. 2C) (Kwon et al., 2008). Thus, iav was required for larvae to sense the preferred temperature, $17.5^{\circ} \mathrm{C}$, over moderately cool temperatures (14$16^{\circ} \mathrm{C}$ ), but was dispensable for choosing $17.5^{\circ} \mathrm{C}$ over cooler $\left(12^{\circ} \mathrm{C}\right)$ or comfortably warm temperatures.

Larval chordotonal neurons function in temperature discrimination in the cool but not the cold range

Several observations indicated that chordotonal neurons were the cells required for discriminating $17.5^{\circ} \mathrm{C}$ from slightly cooler temperatures $\left(14-16^{\circ} \mathrm{C}\right)$, but not other temperatures. First, we generated an iav-GAL4 line, which drove UAS-mCD8GFP expression exclusively in chordotonal neurons (Fig. $3 A$ ), consistent with a previous report that expression of $i a v$ is specific to chordotonal neurons (Gong et al., 2004). To test whether the chordotonal neurons were critical for cool sensation, we inhibited synaptic transmission in these cells by combining the iav-GAL4 with UAS-TNT (tetanus toxin), and found that it prevented temperature discrimination between $14^{\circ}$ and $17.5^{\circ} \mathrm{C}$ (Fig. $3 B$ ). However, there was no impairment on selection of $17.5^{\circ} \mathrm{C}$ over other temperatures such as $12^{\circ}$ or $24^{\circ} \mathrm{C}$ (Fig. $2 \mathrm{~B}, \mathrm{C}$ ). Expression of the inactive form of tetanus toxin had no effect on $17.5^{\circ}$ versus $14^{\circ} \mathrm{C}$ selection (UAS-IMPTNT; Fig. $3 B$ ). Second, the combination of UAS-iav and iav-GAL4 was sufficient to rescue the iav phenotype (Fig. $3 B$ ). Third, we found that expression of UAS-iav under control of either of two additional chordotonal GAL4 lines (nanGAL4 and pain-GAL4) (Tracey et al., 2003; Gong et al., 2004) rescued the deficit in cool temperature discrimination in $i a v^{1}$ larvae (Fig. 3B). Fourth, mutations (ato ${ }^{W}$ and $b t v^{B G 01771}$ ) that impaired the normal development of chordotonal neurons caused a defect in discriminating $14^{\circ}$ and $17.5^{\circ} \mathrm{C}$ (Fig. $3 B$ ). Reintroduction of $U A S$-iav using the only available terminal organ GAL4 (GH86-GAL4) did not rescue the $i a v^{1}$ phenotype, although this result was not reliable since we found that expression of the GH86-GAL4 alone impaired temperature selection (data not shown). Nevertheless, the four lines of evidence presented here support the conclusion that the chordotonal neurons are critical for selection of the optimal over cool temperatures.

\section{Chordotonal neurons and iav contribute to thermal avoidance and increased turning behavior at cool temperatures}

There are at least two mechanisms that potentially underlie the iav-dependent temperature preference behavior. The chordotonal neurons and iav could be required for attraction to the preferred temperature $\left(17.5-18^{\circ} \mathrm{C}\right)$ or for avoidance of modestly cool temperatures $\left(14-16^{\circ} \mathrm{C}\right)$. To distinguish between these possibilities, we attempted to stimulate iav-expressing neurons, in- 

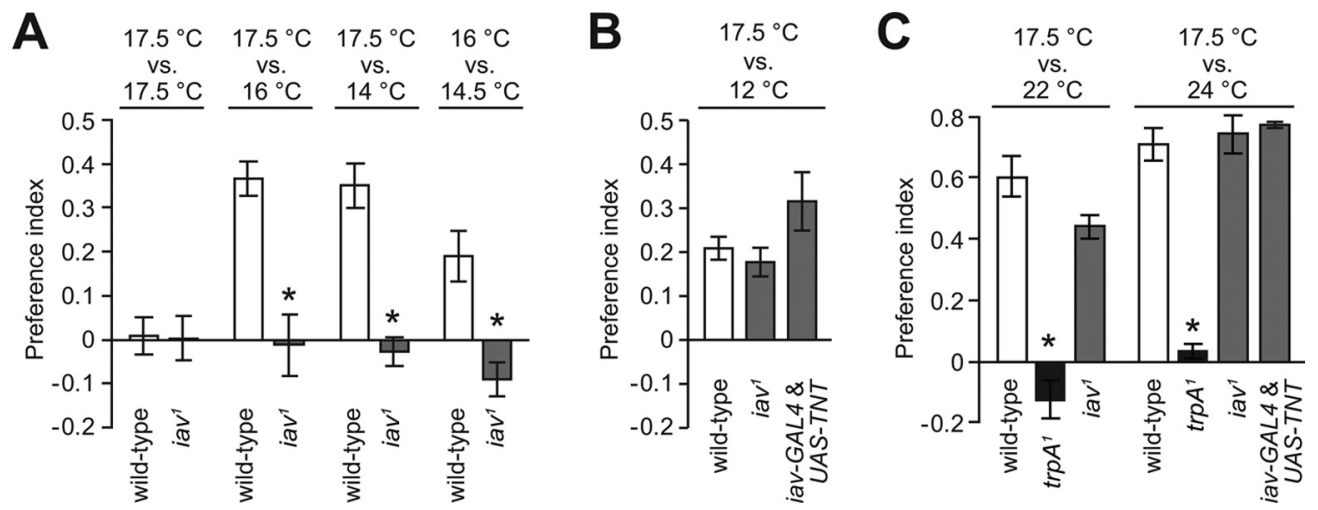

Figure 2. iav is not required for sensing cold and warm temperatures. $A$, iav $^{1}$ is defective in choosing $17.5^{\circ}$ over $14-16^{\circ}$. $B$, iav and the chordotonal organs are not required for discrimination of $17.5^{\circ}$ over $12^{\circ} \mathrm{C}$. C, iav and the chordotonal neurons are not required for selecting $17.5^{\circ} \mathrm{C}$ over comfortably warm temperatures. Asterisks indicate significant differences ( $\left.p<0.05\right)$ with wild type.

dependent of changes in temperatures, and examined whether this induced attractive or avoidance behavior. To activate iav-expressing cells, we expressed channelrhodopsin 2 (UAS-ChR2) (Schroll et al., 2006) under the control of the iavGAL4. ChR2 is a blue light-activated cation channel, so stimulation with blue but not red light leads to depolarization of neurons. Wild-type larvae express rhodopsins (Sprecher et al., 2007), which are classical G-protein coupled receptors. Consequently, in the absence of ChR2, wild-type larvae display an aversive response to light (Hassan et al., 2000). To eliminate the endogenous light response, we tested the effects of introducing the iav-GAL4 and UAS-ChR2 in a norpA $A^{P 24}$ background, which disrupts a phospholipase $\mathrm{C}$ critical for the larval photoresponse (Hassan et al., 2000).

To determine the behavioral consequences resulting from stimulating iavexpressing neurons with ChR2, we placed the larvae in the middle of a Petri dish, half of which was kept in the dark, and the other half was exposed to light (Fig. 4A-D). Wild-type larvae avoided blue light, since they express rhodopsins that absorb blue light, including Rh5 (Fig. 4E) (Sprecher et al., 2007). However, norp $A^{P 24}$ larvae did not show a preference for either the dark or light zones. In contrast, expression of UASChR2 under the control of iav-GAL4 restored the ability of nor$p A^{P 24}$ larvae to move away from the light (Fig. $4 E$ ). This behavior required blue light, consistent with the spectral sensitivity of ChR2. If the norpA ${ }^{P 24} ; \mathrm{iav}-G A L 4 /+; U A S-C h R 2 /+$ larvae were fed on food, which was free of all-trans-retinal, they were unable to discriminate between the dark and light sides (Fig. $4 E$ ). We obtained indistinguishable results using the nan-GAL4 to direct expression of UAS-ChR2 in a norp $A^{P 24}$ background (Fig. $4 E$ ). Since stimulation of $i a v$ - or nan-expressing cells with light induced avoidance responses, these data indicated that wild-type larvae preferred $17.5^{\circ}$ over $14-16^{\circ} \mathrm{C}$ through an avoidance response that required chordotonal neurons.

To explore further the behavioral basis for the iav-dependent avoidance of $14^{\circ} \mathrm{C}$, we tested whether larvae displayed increased turning at the lower temperature. To test this proposal, we tracked the turning behavior of individual larvae at $17.5^{\circ}$ and

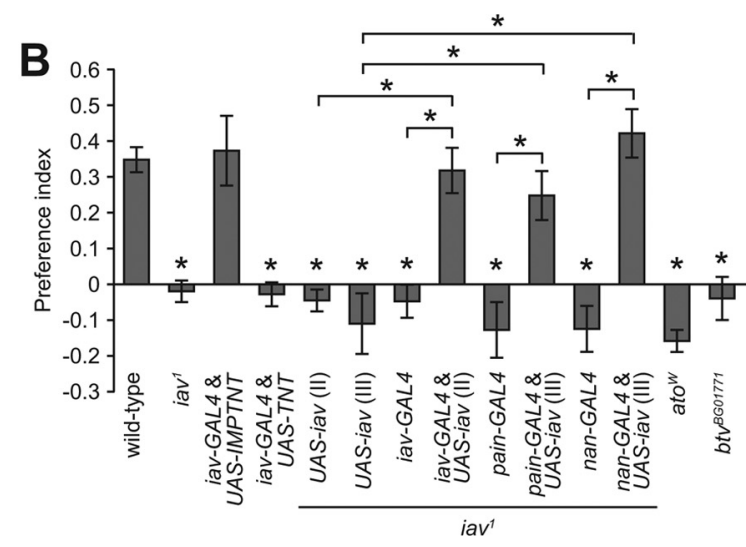

Figure 3. Requirement for chordotonal neurons for $\operatorname{cool}\left(14-16^{\circ} \mathrm{C}\right)$ avoidance behavior. $A$, iav reporter expression in larvae. The top shows GFP expression in chordotonal neurons (white arrowhead) in first instar larva using the iav-GAL4 and UAS-mCD8-GFP transgenes. The open arrowheads indicate the position of the terminal organs, which are not labeled. Anterior is to the left. The gut $14^{\circ} \mathrm{C}$ in iav ${ }^{7}$ was rescued by expressing UAS-iav in chordotonal neurons. ato ${ }^{w}$ and $b t v^{B G 01771}$ showed defects in selection of $17.5^{\circ}$ over $14^{\circ} \mathrm{C}$. Asterisks indicate significant differences $(p<0.05)$ with wild type.

$14^{\circ} \mathrm{C}$. After establishing the initial movement trajectory (initial trajectory, Fig. $4 F)$, we determined the angle of deviation ( $\theta$; turning angle) from the initial trajectory over the $5.1 \mathrm{~s}$ interval between frames (Fig. $4 F$ ). We found that wild-type larvae showed an increase in the average turning angle at $14^{\circ} \mathrm{C}$ compared with $17.5^{\circ} \mathrm{C}$ (Fig. $4 G$ ). The percentage of lower angle turns $(\theta=$ $\left.0-45^{\circ}\right)$ decreased while the percentage of medium angle turns $\left(45-90^{\circ}\right)$ increased at $14^{\circ} \mathrm{C}$ (Fig. $\left.4 \mathrm{H}\right)$. However, the percentage of high angle turns $\left(\theta=90-180^{\circ}\right)$ were similar at $14^{\circ}$ and $17.5^{\circ} \mathrm{C}$ (Fig. $4 \mathrm{H})$. Moreover, the total number of turns $\left(\theta \geq 45^{\circ}\right)$ nearly doubled (Fig. 4 J; supplemental Fig. 1, available at www.jneurosci. org as supplemental material).

In contrast to wild-type, in $i a v^{l}$ mutant larvae, the total number of turns $\left(\theta \geq 45^{\circ}\right)$ and the average turning angles did not increase at $14^{\circ} \mathrm{C}$ (Fig. $4 \mathrm{G}$, J; supplemental Fig. 1, available at www. jneurosci.org as supplemental material). At $17.5^{\circ} \mathrm{C}, i a v^{l}$ larvae displayed average turning angles similar to wild-type larvae (Fig. $4 G$ ). This value did not increase at $14^{\circ} \mathrm{C}$ (Fig. $4 G$ ), and the percentages of low, medium and high angle turns were unchanged at the two temperatures (Fig. 4I). Even though $i a v^{1}$ larvae moved slower than wild-type larvae, the vectoral distance between the starting and ending points was similar to that of wild type at $14^{\circ} \mathrm{C}$, 
A

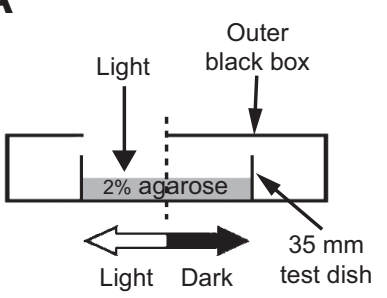

B

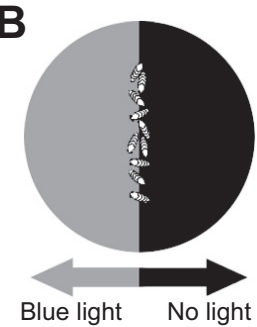

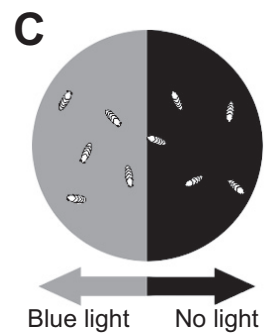

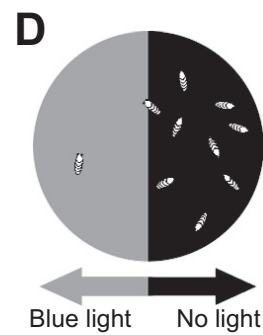

E

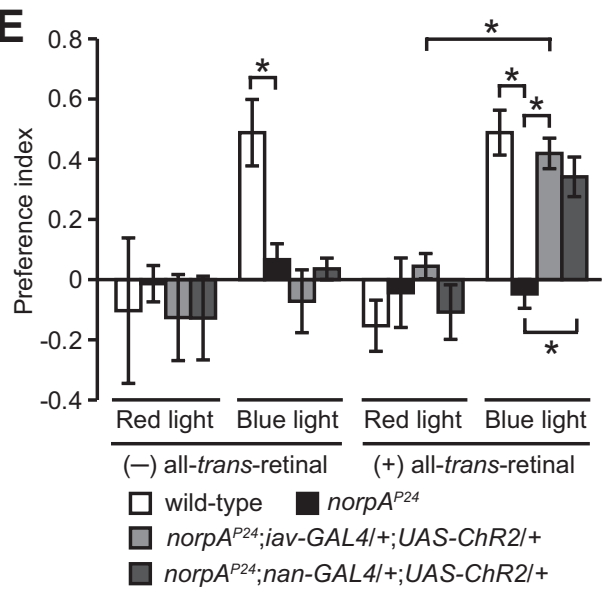

$\mathbf{F}$
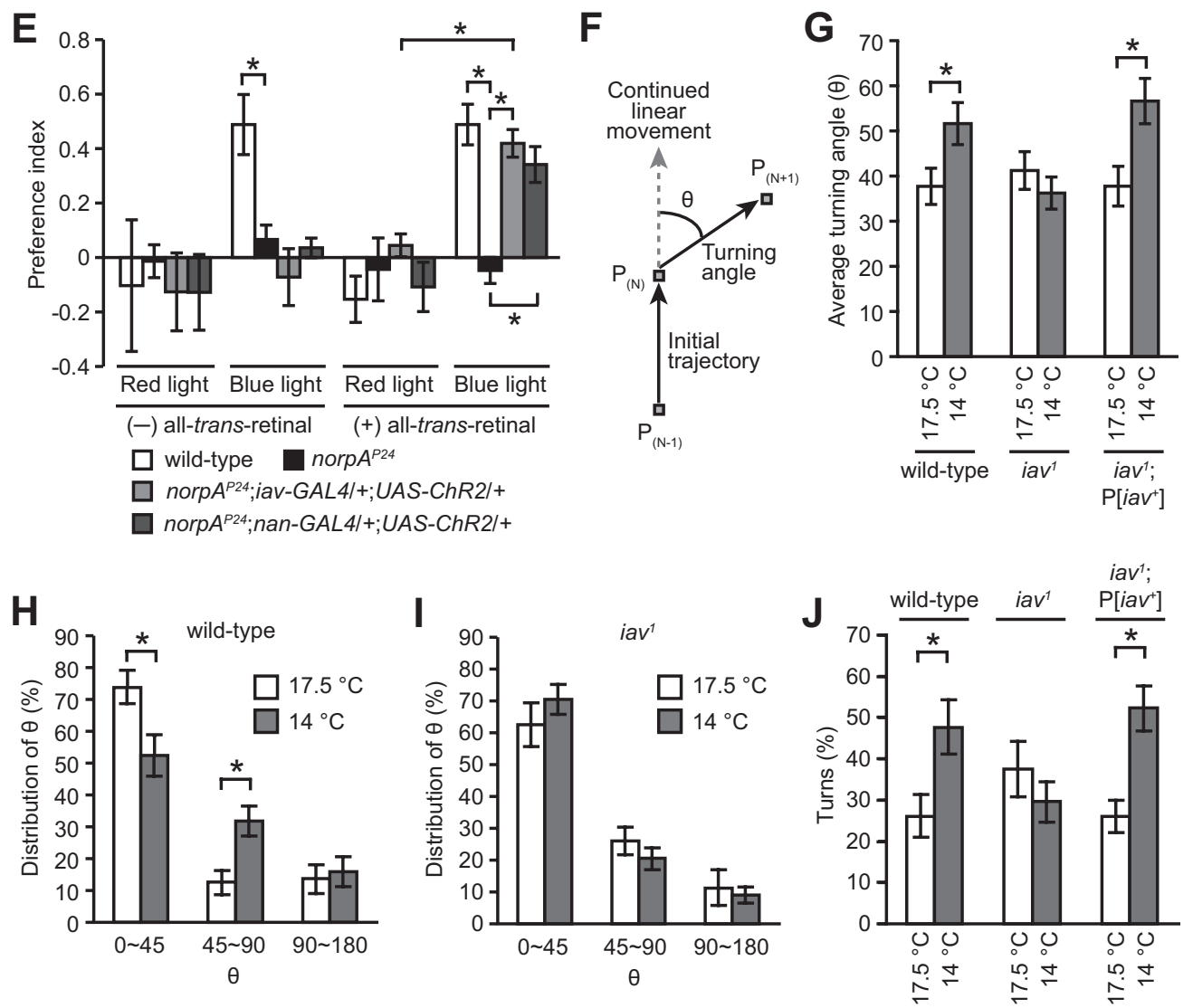

Figure 4. Requirement for iav for cool temperature-induced turning. A-D, Setup for testing whether temperature independent activation of chordotonal neurons induced an attractive or avoidance response. We expressed a ChR2 transgene (UAS-ChR2 transgene) under the control of the iav-GAL4 or the nan-GAL4 in a norpA ${ }^{\text {P24 }}$ background. Blue- but not red light-activated ChR2. As controls, we analyzed wild-type and norp $A^{P 24}$ flies in the presence of blue or red light. Experiments with blue light are depicted. $A$, Side view of the setup. A semicircle (3.5 $\mathrm{cm}$ in diameter) was removed from the top lid of a black box to allow one side of the Petri dish (3.5 $\mathrm{cm} ; 2 \%$ agarose), which was inserted into the box, to be exposed to illumination. $\boldsymbol{B}$, Larvae were released along the middle of the dish. $\boldsymbol{C}$, norpA ${ }^{P 24}$ larvae randomly distributed throughout the dish in response to blue light. $\boldsymbol{D}$, norpA ${ }^{P 24} ;$;iav-GAL4/+;UAS-Chr2/+ larvae and norpA ${ }^{P 24} ;$ nan-GAL4/UAS-Chr2 larvae avoided blue light when they were fed all-trans-retinal. $E$, Involvement of iav-expressing neurons in avoidance behavior. We eliminated the intrinsic light response using the norp $A^{P 24} \mathrm{mutation}$. The larvae were reared on food with or without all-trans-retinal and exposed to blue or red light as indicated. Complete preferences for the dark and light sides would produce P.I. values of 1.0 and -1.0 , respectively. A lack of preference would result in a P.I. of 0 . $F$, Measurement of turning angles $(\theta)$. The $\theta$ values were calculated using coordinates $\left(P_{(\mathrm{N}-1)}, P_{(\mathrm{N})}\right.$, and $\left.P_{(\mathrm{N}+1)}\right)$ in three consecutive frames. The initial linear movement (initial trajectory) was the vector connecting $P_{(\mathrm{N}-1)}$ to $P_{(\mathrm{N})}$. The $\theta$ was based on the initial trajectory and the vector connecting $P_{(\mathrm{N})}$ to $P_{(\mathrm{N}+1)}$. $G$, Average $\theta$ at $14^{\circ}$ and $17.5^{\circ} \mathrm{C} . \boldsymbol{H}, \boldsymbol{I}$, Percentage distribution of $\theta\left(\boldsymbol{H}\right.$, wild type; $\left.\boldsymbol{I}, \boldsymbol{i a v}^{\top}\right)$. $\boldsymbol{J}$, The percentage of frames in which larvae made a turn $\geq 45^{\circ}$. Asterisks indicate significant differences $(p<0.05)$ with wild type, unless indicated with a bracket.

due to the lower turning angles (supplemental Fig. $2 \mathrm{~A}$, available at www.jneurosci.org as supplemental material). Thus, $i a v^{1}$ larvae traveled as far as wild-type larvae and were able to survey as large a proportion of the thermal environment as the wild type. This is in contrast to nan $^{36 a}$ mutant larvae, which traveled half the vectoral distance of wild-type and $i a v^{1}$ larvae (supplemental Fig. $2 A$, available at www.jneurosci.org as supplemental material) due to a combination of slow movement and high turning at both $14^{\circ}$ and $17.5^{\circ} \mathrm{C}$ (supplemental Fig. $2 \mathrm{~B}, \mathrm{C}$ ). Introduction of the wild-type $i a v^{+}$transgene in $i a v^{1}$ restored the wild-type increase in the number of turns and average turning angle at $14^{\circ} \mathrm{C}$ (Fig. $4 G$; supplemental Fig. $2 D$, available at www.jneurosci.org as supple- mental material). Based on these analyses, we suggest that iav is required for choosing the preferred temperature $\left(17.5^{\circ} \mathrm{C}\right)$ over the cool temperature $\left(14^{\circ} \mathrm{C}\right)$ through avoidance of $14^{\circ} \mathrm{C}$, and this behavior is mediated by increases in the number of turns and turning angles at this lower temperature.

\section{Discussion}

A key goal in behavioral neurobiology is to define the cellular and molecular determinants that enable animals to decide between two or more alternative actions based on environmental cues. Thermotactic discrimination in Drosophila larvae represents a simple model to address the interplay between sensory input and 
choice selection. In the current study, we defined the cellular and molecular requirements for selection of slightly cool over the optimal temperature, and demonstrated how the cells and TRP channels contribute to thermotactic behavior. Specifically, we found that the chordotonal neurons functioned in the discrimination of $17.5^{\circ} \mathrm{C}$ and slightly cooler temperatures, and this required a TRPV channel, Iav. In support of a requirement for the chordotonal neurons, the effect due to loss of iav was reversed by introduction of the wild-type gene in chordotonal neurons. Moreover, expression of tetanus toxin in chordotonal neurons suppressed the ability to select 17.5 over $14^{\circ} \mathrm{C}$, consistent with a requirement for synaptic transmission from the chordotonal neurons for cool temperature discrimination.

It has been reported previously that the terminal organs are involved in selecting $18^{\circ} \mathrm{C}$ over $11^{\circ} \mathrm{C}$ (Liu et al., 2003). We found that the chordotonal neurons and iav were not required for selecting the optimal temperature over temperatures cooler than $14^{\circ} \mathrm{C}$. We propose that the chordotonal organ functions in the discrimination of $17.5^{\circ} \mathrm{C}$ versus slightly cooler temperatures $\left(14-16^{\circ} \mathrm{C}\right)$, while the terminal organ functions in the selection of $17.5^{\circ} \mathrm{C}$ over $12^{\circ} \mathrm{C}$ and cooler temperatures.

The finding that Iav was required for choosing the optimal temperatures over slightly cool temperatures underscores the broad evolutionary role for TRPV channels in temperature selection. However, the requirement for Iav is distinct from mammalian TRPVs, several of which function in the responses to warm or hot temperatures (Bandell et al., 2007; Venkatachalam and Montell, 2007). Whether the other Drosophila TRPV, Nan, also contributes to temperature selection is unclear, since the thermotaxis assay was complicated by the greater sedentary behavior than iav, and the abnormally high turning even at $17.5^{\circ} \mathrm{C}$. As a result, the nan larvae traveled small distances and remained near the initial site in which they were placed. Nevertheless, as is the case for Iav, the Nan channel is also expressed in chordotonal neurons, and therefore could potentially function in cool sensation (Gong et al., 2004). However, at least one other TRP channel, Pain, is expressed in chordotonal neurons (Tracey et al., 2003), but is not required for choosing $17.5^{\circ} \mathrm{C}$ over mildly cool temperatures.

In addition to Iav, another TRP channel, TRPL, functions in cool sensation (Rosenzweig et al., 2008). As was previously reported for TRPL (Rosenzweig et al., 2008), expression of Iav in oocytes did not elicit a cool-activated current (data not shown). Thus, it is not clear whether activation of either of these channels by thermal cool is direct or indirect. In contrast to iav and trpl, we did not detect a requirement for trp in temperature discrimination in the cool range, which differs from a previous report (Rosenzweig et al., 2008). However, a role for $\operatorname{trp}$ was less clear, given the lack of phenotype when the trp mutation was placed in trans with a deficiency, which uncovered the gene (Rosenzweig et al., 2008). Nevertheless, given that the previous and current studies focused on early and late stage larvae respectively, we cannot exclude that there are developmental differences in requirements for the TRP channel for sensing mildly cool temperatures.

Even though wild-type third instar larvae prefer $17.5^{\circ} \mathrm{C}$ over any other temperature, we found that the P.I. increased significantly in proportion to the alternative temperature $\left(\sim 0.2,12^{\circ} \mathrm{C}\right.$; $\left.\sim 0.35,14^{\circ} \mathrm{C} ; \sim 0.7,24^{\circ} \mathrm{C}\right)$. We suggest that these differences are only partially due to the slower movements at the lower temperatures. The variations in the average P.I. values may reflect differences in the molecules, mechanisms and cell types involved in discriminating the optimal temperature $\left(17.5^{\circ} \mathrm{C}\right)$ from mildly $\operatorname{cool}\left(14-16^{\circ} \mathrm{C}\right), \operatorname{cool}\left(12^{\circ} \mathrm{C}\right)$ and comfortably warm $\left(22-24^{\circ} \mathrm{C}\right)$ temperatures. In support of this proposal, inhibition of neurotransmission in chordotonal neurons specifically impaired the ability to discriminate between the preferred temperature over $14^{\circ} \mathrm{C}$ (Fig. $2 \mathrm{~B}, \mathrm{C}$ ), and did not reduce selection of $17.5^{\circ}$ over either $12^{\circ} \mathrm{C}$ or $24^{\circ} \mathrm{C}$. Furthermore, a Gq/phospholipase C/TRPA1 thermosensory signaling cascade participates in choosing the optimal temperature over other temperatures in the comfortable range $\left(20-24^{\circ} \mathrm{C}\right)$ (Kwon et al., 2008), while Iav and TRPL are required for opting for $17.5^{\circ} \mathrm{C}$ over mildly cool temperatures.

A critical question is how the thermotactic selection of the optimal over mildly cooler temperatures is accomplished via the chordotonal neurons and iav. The following three observations lead us to propose a model. First, iav mutant animals retain the ability to select the optimal temperature over very cool and comfortably warm temperatures. These results argue against a requirement for iav for positive selection of $17.5^{\circ} \mathrm{C}$ only, since this optimal temperature is still selected versus some temperatures. Second, stimulation of iav-expressing neurons with channelrhodopsin induces an avoidance response to light. Third, the modestly cooler temperature increased the average turning angles and the total number of turns $\left(\theta \geq 45^{\circ}\right)$ relative to wild type. Thus, we conclude that iav-dependent decision to choose the optimal over slightly cooler temperatures is mediated by increased activity of chordotonal neurons, which stimulates an avoidance response by increasing the number and magnitude of turning angles.

\section{References}

Bandell M, Macpherson LJ, Patapoutian A (2007) From chills to chilis: mechanisms for thermosensation and chemesthesis via thermoTRPs. Curr Opin Neurobiol 17:490-497.

Brand AH, Perrimon N (1993) Targeted gene expression as a means of altering cell fates and generating dominant phenotypes. Development 118:401-415.

Choi CM, Vilain S, Langen M, Van Kelst S, De Geest N, Yan J, Verstreken P, Hassan BA (2009) Conditional mutagenesis in Drosophila. Science 324:54.

Gong Z, Son W, Chung YD, Kim J, Shin DW, McClung CA, Lee Y, Lee HW, Chang DJ, Kaang BK, Cho H, Oh U, Hirsh J, Kernan MJ, Kim C (2004) Two interdependent TRPV channel subunits, Inactive and Nanchung, mediate hearing in Drosophila. J Neurosci 24:9059-9066.

Hamada FN, Rosenzweig M, Kang K, Pulver SR, Ghezzi A, Jegla TJ, Garrity PA (2008) An internal thermal sensor controlling temperature preference in Drosophila. Nature 454:217-220.

Hassan J, Busto M, Iyengar B, Campos AR (2000) Behavioral characterization and genetic analysis of the Drosophila melanogaster larval response to light as revealed by a novel individual assay. Behav Genet 30:59-69.

Hofmann T, Chubanov V, Chen X, Dietz AS, Gudermann T, Montell C (2010) Drosophila TRPM channel is essential for the control of extracellular magnesium levels. PLoS ONE 5:e10519.

Kim J, Chung YD, Park DY, Choi S, Shin DW, Soh H, Lee HW, Son W, Yim J, Park CS, Kernan MJ, Kim C (2003) A TRPV family ion channel required for hearing in Drosophila. Nature 424:81-84.

Kwon Y, Shim HS, Wang X, Montell C (2008) Control of thermotactic behavior via coupling of a TRP channel to a phospholipase $\mathrm{C}$ signaling cascade. Nat Neurosci 11:871-873.

Lee Y, Lee J, Bang S, Hyun S, Kang J, Hong ST, Bae E, Kaang BK, Kim J (2005) Pyrexia is a new thermal transient receptor potential channel endowing tolerance to high temperatures in Drosophila melanogaster. Nat Genet 37:305-310.

Liu L, Yermolaieva O, Johnson WA, Abboud FM, Welsh MJ (2003) Identification and function of thermosensory neurons in Drosophila larvae. Nat Neurosci 6:267-273.

Niemeyer BA, Suzuki E, Scott K, Jalink K, Zuker CS (1996) The Drosophila light-activated conductance is composed of the two channels TRP and TRPL. Cell 85:651-659.

Rosenzweig M, Brennan KM, Tayler TD, Phelps PO, Patapoutian A, Garrity PA (2005) The Drosophila ortholog of vertebrate TRPA1 regulates thermotaxis. Genes Dev 19:419-424. 
Rosenzweig M, Kang K, Garrity PA (2008) Distinct TRP channels are required for warm and cool avoidance in Drosophila melanogaster. Proc Natl Acad Sci U S A 105:14668-14673.

Schroll C, Riemensperger T, Bucher D, Ehmer J, Völler T, Erbguth K, Gerber B, Hendel T, Nagel G, Buchner E, Fiala A (2006) Light-induced activation of distinct modulatory neurons triggers appetitive or aversive learning in Drosophila larvae. Curr Biol 16:1741-1747.

Sprecher SG, Pichaud F, Desplan C (2007) Adult and larval photoreceptors use different mechanisms to specify the same Rhodopsin fates. Genes Dev 21:2182-2195.

Tracey WD Jr, Wilson RI, Laurent G, Benzer S (2003) painless, a Drosophila gene essential for nociception. Cell 113:261-273.
Venkatachalam K, Montell C (2007) TRP channels. Annu Rev Biochem 76:387-417.

Venkatachalam K, Long AA, Elsaesser R, Nikolaeva D, Broadie K, Montell C (2008) Motor deficit in a Drosophila model of mucolipidosis type IV due to defective clearance of apoptotic cells. Cell 135:838-851.

Walker RG, Willingham AT, Zuker CS (2000) A Drosophila mechanosensory transduction channel. Science 287:2229-2234.

Wang T, Jiao Y, Montell C (2005) Dissecting independent channel and scaffolding roles of the Drosophila transient receptor potential channel. J Cell Biol 171:685-694.

Watnick TJ, Jin Y, Matunis E, Kernan MJ, Montell C (2003) A flagellar polycystin-2 homolog required for male fertility in Drosophila. Curr Biol 13:2179-2184. 